\title{
Use of Organomolybdenum Compounds for Promoted Hydrolysis of Phosphoester Bonds in Aqueous Media
}

Carla A. Gamelas,[a] Ana C. Gomes,[c] José A. Fernandes,[c] Filipe A. Almeida Paz,[c] Patrique Nunes,[d] Martyn Pillinger,[c] Isabel S. Gonçalves,[c] Carlos C. Romão,[b] and Marta Abrantes [d]

[a] Escola Superior de Tecnologia, Instituto Politécnico de Setúbal, 2910-761 Setúbal, Portugal

[b] Instituto de Tecnologia Química e Biológica da Universidade Nova de Lisboa, Av. da República, Estação Agronómica Nacional, 2780-157 Oeiras, Portugal

[c] Department of Chemistry, CICECO, University of Aveiro, Campus Universitário de Santiago, 3810-193 Aveiro, Portugal

[d] Centro de Química Estrutural, Complexo Interdisciplinar, Instituto Superior Técnico, Universidade de Lisboa, 1049-001 Lisbon, Portugal

E-mail: carla.gamelas@estsetubal.ips.pt

Keywords: Molybdenum / Indenyl ligands / Oxido ligands / Phosphoesters / Hydrolysis

Organophosphate pesticides are one of the most significant causes of severe toxicity and death from acute poisoning worldwide, being responsible for more than 200000 deaths each year in developing countries.[1] Moreover, their accumulation in the environment is a recognized ecological threat, as they have harmful effects on mammalian species owing to long-term exposure to sublethal doses.[2]

Hydrolysis is considered to be a possible strategy to eliminate organophosphate pesticides (since the hydrolysis products have a substantially lower toxicity), but in the absence of a catalyst or enzyme, phosphoester hydrolysis is extremely slow. For this reason, a growing interest in the metal promoted hydrolysis of phosphoesters has arisen.

As part of our work to explore molybdenum compounds for the promoted hydrolysis of phosphoesters $[3,4]$, in the present work [5] we have studied the performance of the dimeric chloride complex $\left[\left\{\left(\eta^{5}-\mathrm{Ind}\right) \mathrm{Mo}(\mathrm{CO})_{2}(\mu-\mathrm{Cl})\right\}_{2}\right](\mathbf{1}$; Ind = indenyl) as a hydrolysis promoting agent of para-nitrophenylphosphate $(p N P P)$ to give para-nitrophenol ( $p N P h)$ and inorganic phosphate (Scheme 1).

In this study, we further report that the dissolution of $\mathbf{1}$ in $\mathrm{N}, \mathrm{N}$-dimethylformamide (DMF) gives the ring-slipped complex $\left[\left(\eta^{3}-\mathrm{Ind}\right) \mathrm{Mo}(\mathrm{CO})_{2} \mathrm{Cl}(\mathrm{DMF})_{2}\right]$ (2), which subsequently can undergo aerial oxidation to give the dinuclear oxomolybdenum(V) chloride $\left[\mathrm{Mo}_{2} \mathrm{O}_{2}(\mathrm{DMF})_{4}(\mu-\mathrm{O})_{2} \mathrm{Cl}_{2}\right]$ (3) (Scheme 2). The structures of 2 and 3.DMF have been determined by single-crystal $\mathrm{X}$-ray diffraction.

Compound 3 was also examined as a hydrolysis-promoting agent and the results are compared with those obtained for $\mathrm{Mo}(\mathrm{CO})_{6}$ and $\left[\mathrm{MoO}_{2} \mathrm{Cl}_{2}(\mathrm{DMF})_{2}\right] .[3,4]$ For assays performed with $30-100$ mol-\% of 1 or 3 relative to pNPP in aqueous media, both compounds promote the production of $p N P h$ from $p N P P$, compound 3 being very efficient with $t_{1 / 2}<80 \mathrm{~min}$.

[1] M. Eddleston, N. A. Buckley, P. Eyer, A. H. Dawson, Lancet 2008, 371, 597-607

[2] M. Sirotkina, I. Lyagin, E. Efremenko, Int. Biodeterior. Biodegrad. 2012, 68, 18-23 
[3] C. Tomé, M. C. Oliveira, M. Pillinger, I. S. Gonçalves, M. Abrantes, Dalton Trans. 2013, 42, 3901-3907

[4] A. C. Gomes, M. Pillinger, P. Nunes, I. S. Gonçalves, M. Abrantes, J. Organomet. Chem. 2014, 760, 42-47

[5] A. C. Gomes, C. A. Gamelas, J. A. Fernandes, F. A. Almeida Paz, P. Nunes, M. Pillinger, I. S. Gonçalves, C. C. Romão, M. Abrantes, Eur. J. Inorg. Chem. 2014, 36813689

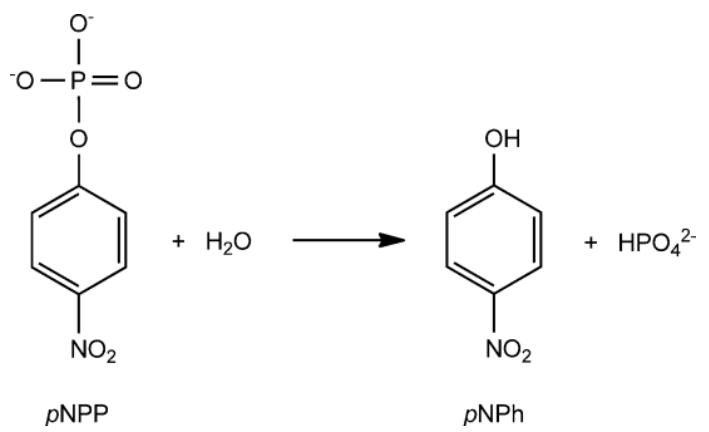

Scheme 1. Hydrolysis of para-nitrophenylphosphate ( $p N P P)$ to give para-nitrophenol $(p N P h)$

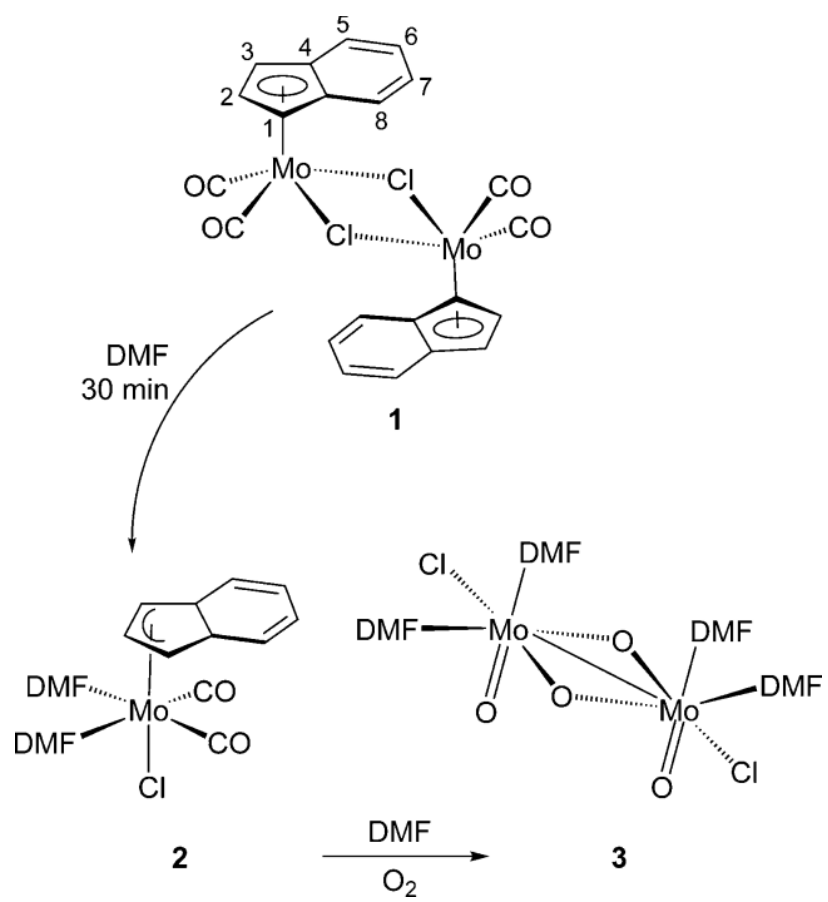

Scheme 2. Synthesis of 2 and $\mathbf{3}$ from $\mathbf{1}$ 